\title{
Investigation of the parameters influencing progress of concrete carbonation depth by using artificial neural networks
}

\author{
P. Akpinar $\bowtie$, I.D. Uwanuakwa \\ Civil Engineering Department, Faculty of Civil and Environmental Engineering, Near East University, TRNC (Turkey) \\ $\varangle$ : pinar.akpinar@neu.edu.tr
}

Received 14 February 2019

Accepted 4 September 2019

Available on line 21 January 2020

\begin{abstract}
Carbonation is a deleterious concrete durability problem which may alter concrete microstructure and yield initiation of corrosion in reinforcing steel bars. Previous studies focused on the use of Artificial Neural Networks (ANN) for the prediction of concrete carbonation depth and to minimize the need for destructive and elaborated civil engineering laboratory tests. This study aims to provide improved accuracy of simulation and prediction of carbonation with an $\mathrm{ANN}$ architecture including eighteen input parameters employing alternative Scaled Conjugate Gradient (SCG) function. After ensuring a promising value of the coefficient of correlation as high as 0.98 , the influence of proposed input parameters on the progress of carbonation depth was studied. The results of this parametric analysis were observed to successfully comply with the conventional civil engineering experience. Hence, the employed ANN model can be used as an efficient tool to study in detail and to provide insights into the carbonation problem in concrete.
\end{abstract}

KEYWORDS: Concrete; Fly ash; Durability; Carbonation; Modelization.

Citation/Citar como: Akpinar, P.; Uwanuakwa, I.D. (2020) Investigation of the parameters influencing progress of concrete carbonation depth by using artificial neural networks. Mater. Construcc. 70 [337], e209 https://doi. org/10.3989/mc.2020.02019

RESUMEN: Investigación de los parámetros que influyen en el progreso de la profundidad de carbonatación del hormigón usando redes neuronales artificiales. La carbonatación es un problema perjudicial de durabilidad del hormigón que puede alterar la microestructura del hormigón y provocar el inicio de la corrosión en barras de refuerzo. Estudios previos se centraron en el uso de redes neuronales artificiales (RNA) para la predicción de la profundidad de la carbonatación del hormigón y para minimizar la necesidad de pruebas de laboratorio destructivas y elaboradas. Este estudio tiene como objetivo proporcionar una precisión mejorada de la simulación y la predicción de la carbonatación con una arquitectura RNA que incluye dieciocho parámetros de entrada con una función alternativa de Gradiente de Conjugado Escalado. Después de asegurar un valor prometedor del coeficiente de correlación tan alto como 0.98 , se estudió la influencia de los parámetros de entrada propuestos en el progreso de la profundidad de carbonatación. Se observó que los resultados de este análisis paramétrico cumplían exitosamente con la experiencia de ingeniería civil convencional. Por lo tanto, el modelo RNA empleado puede ser utilizado como una herramienta eficiente para estudiar en detalle y proporcionar información sobre el problema de carbonatación en el hormigón.

PALABRAS CLAVE: Hormigón; Cenizas volantes; Durabilidad; Carbonatación; Modelización.

ORCID ID: P. Akpinar (http://orcid.org/0000-0002-6885-8105); I.D. Uwanuakwa (http://orcid.org/0000-0001-5546-0408)

Copyright: (C) 2020 CSIC. This is an open-access article distributed under the terms of the Creative Commons Attribution 4.0 International (CC BY 4.0) License. 


\section{INTRODUCTION}

Carbonation problem in concrete structures results in the formation of calcium carbonate due to the neutralization reaction between calcium hydroxide and carbonic acid, which yielded by the ingress of $\mathrm{CO}_{2}$ gas from the atmosphere into the concrete microstructure. $(1,2)$. As a result, the microstructure of hardened cement paste is altered and the $\mathrm{pH}$ level of the concrete decreases from 13.5 to 9.5 (3). These changes are known to lead to de-passivation of reinforcement bars' protective layer $(3,4)$. Consequently, oxygen supply and moisture may initiate corrosion of reinforcement bars.

Determining the progress of concrete carbonation depth, which is known to depend on several factors, is critical for the evaluation of the performance of reinforced concrete structures throughout their service lives; since the initiation of carbonation-induced corrosion of reinforcing bars might cause severe damages in concrete (3). Conventional experimental methods for the determination of carbonation depth in concrete are generally destructive, elaborate and commonly fail to provide detailed information on the extent of the effect of each influencing factor on the progress of the problem (5). Therefore, a non-destructive model capable of considering different concrete-related parameters individually and predicting the extent (i.e. the depth) of carbonation in concrete that could be exposed to varying environmental conditions within a specified exposure period is required. Such a model would provide extended understanding of carbonation process, and could contribute to the improvement of other holistic studies aiming to determine the general performance of reinforced concrete structures during their service lives.

Artificial neural networks (ANN) applications have been used effectively for several decades for simulation and prediction of varying case studies in both applied and social sciences $(6,7)$. It generalizes new inputs based on acquired knowledge of past experience. ANN has been previously used only to an extent in the field of concrete carbonation depth prediction (8-11). Majority of these previous studies are based on the limited amount of data and generally focus on the use of Levenberg-Marquardt function due to its speed of convergence and measure the network performance from the values of $\mathrm{R}$ (correlation coefficient) and measured errors.

This study, proposes an ANN model that considers eighteen environmental and concrete-related input parameters; and based on their selection, provides an estimation for the extent of the resultant concrete carbonation, as an efficient alternative to conventional laboratory experiments done by phenolphthalein indicator methods. Beside its advantageous use in carbonation depth determination, a viable intelligent prediction method has also the potential to enable researchers working in the field of concrete carbonation to gain further insights on the effect of each influencing parameters in a systematically way; without needing to carry out the "time, resources and labour-consuming" laboratory experiments. This study, which is a continuation of previous work (8), seeks to initially provide an enhanced prediction efficiency by employing an increased amount of data for training and testing, together with the use of Scaled Conjugate Gradient (SCG) function, as an alternative to typically used Levenberg-Marquardt function. After ensuring a high prediction and simulation accuracy, the proposed model was further employed to verify the feasibility of using this model as an intelligent tool for studying the progress of concrete carbonation and to explore the role of key input parameters on this time-dependent concrete durability problem.

\section{METHODOLOGY}

\subsection{Data Acquisition and Preparation}

The progress of carbonation front is known to be governed by cement composition, the composition of additives, concrete mix properties, curing conditions, environmental factors such as relative humidity and temperature, as well as the duration of carbonation attack (12-14). 18 input variables that were identified as influencing the progress of carbonation were employed in the study. These input values are as shown in Table 1. Carbonation depth in $\mathrm{mm}$ was selected as the output variable. Dataset used in this study was extracted from experimental research works from related literature. For this purpose, only the experimental studies in the literature that provided the proposed 18 input and the output (presented in Table 1) with clear units that can be harmonized within each parameter, were selected for the acquisition of the dataset, and any other study failing to provide all of the sought information in this manner was disregarded. As a result, 378 experimental cases in 12 studies $(12,13,15-24)$ that were found to have comparable characteristics, were selected. Even though the chemical compositional information for the binders was carefully extracted and used as inputs, some other critical parameters such as cement's loss on ignition information could not be reached uniformly in all scanned studies. Exact aggregate gradation, admixture inclusion and characteristics are the other concrete parameters that could not be reached systematically. Therefore, their potential effects on the progress of concrete carbonation have not been considered within the scope of this study.

Table 1 also presents related references in the literature that provide information on the relevance of identified input parameters on the carbonation depth; supporting their inclusion to the proposed 
TABLE 1. Descriptive information on the input and output variables defined in the proposed model and the references indicating their relevance to concrete carbonation

\begin{tabular}{|c|c|c|c|c|c|c|}
\hline Variables & Unit & Min & Max & Mean & Std. D & Related References \\
\hline Cement $\mathrm{CaO}$ content & $(\%)$ & 45.7 & 68.02 & 62.19 & 3.63 & $(25)$ \\
\hline Cement $\mathrm{SiO}_{2}$ content & $(\%)$ & 20.21 & 31.2 & 21.71 & 2.45 & $(26,27)$ \\
\hline Cement $\mathrm{Fe}_{2} \mathrm{O}_{3}$ content & $(\%)$ & 1 & 6.15 & 3.41 & 1.03 & $(26,27)$ \\
\hline Cement $\mathrm{Al}_{2} \mathrm{O}_{3}$ content & $(\%)$ & 3.1 & 9.2 & 4.71 & 1.28 & $(26,27)$ \\
\hline Fly Ash $\mathrm{CaO}$ content & $(\%)$ & 0 & 5.2 & 1.43 & 1.65 & $(26,27)$ \\
\hline Fly Ash $\mathrm{SiO}_{2}$ content & $(\%)$ & 0 & 55.3 & 23.98 & 25.85 & $(26,27)$ \\
\hline Fly Ash $\mathrm{Fe}_{2} \mathrm{O}_{3}$ content & $(\%)$ & 0 & 13.92 & 4.75 & 5.55 & $(26,27)$ \\
\hline Fly Ash $\mathrm{Al}_{2} \mathrm{O}_{3}$ content & $(\%)$ & 0 & 30.08 & 12.79 & 13.78 & $(26,27)$ \\
\hline Total cement content & $\left(\mathrm{kg} / \mathrm{m}^{3}\right)$ & 0 & 280 & 50.19 & 83.38 & $(26,27)$ \\
\hline Total fly ash content & $\left(\mathrm{kg} / \mathrm{m}^{3}\right)$ & 67 & 486 & 300.08 & 98.31 & $(28-30)$ \\
\hline Water content & $\left(\mathrm{kg} / \mathrm{m}^{3}\right)$ & 102.12 & 220 & 167.87 & 27.19 & $(28)$ \\
\hline Water/binder ratio & $(\%)$ & 0.28 & 0.84 & 0.49 & 0.11 & (28) \\
\hline Curing time & (days) & 1 & 90 & 31.16 & 22.22 & $(18,31)$ \\
\hline Curing relative humidity & $(\%)$ & 50 & 100 & 89.38 & 18.40 & $(18,31)$ \\
\hline External temperature & $(\mathrm{oC})$ & 12 & 32.5 & 20.67 & 5.19 & $(28,32,33)$ \\
\hline External $\mathrm{CO}_{2}$ content & $(\%)$ & 50 & 100 & 67.37 & 9.09 & $(16,32,34)$ \\
\hline External relative humidity & $(\%)$ & 0.03 & 100 & 20.03 & 24.72 & $(35)$ \\
\hline Carbonation duration & (days) & 3 & 2070 & 180.31 & 334.60 & $(12,13,15-24)$ \\
\hline Carbonation depth & $(\mathrm{mm})$ & 0 & 64.03 & 16.36 & 14.84 & \\
\hline
\end{tabular}

ANN model. Multiple linear regression (MLR) was also additionally employed in order to verify the relationship between the output and the multiple input variables presented in Table 1, and the predictive ability of the constructed MLR equation was checked by the coefficient of determination $\left(\mathrm{R}^{2}\right)$. MLR is one of the most commonly used statistical methods used in the literature which aims to provide an understanding of the behaviour of a dependent variable with several defined independent variables. Silva et al. (36), is one of the examples in the related literature studying carbonation problem in concrete with MLR, even though it is acknowledged that not all influencing parameters' relation with the carbonation progress would be necessarily linear. In their study, an $\mathrm{R}^{2}$ value of 0.712 was reported when a certain range of relative humidity values was considered, and a higher $\mathrm{R}^{2}$ could be observed with another range of the mentioned independent variable. In this study, where the complete ranges of the variables mentioned in Table 1 were considered, the coefficient of determination was obtained as 0.713 ; indicating that $71.3 \%$ of the variations could be defined by changes in the input parameters used. MLR was used as a supplementary tool in this study and further detailed statistical analyses have been considered as out of the scope of this particular work, that is mainly focused on the use of artificial neural networks for prediction of concrete carbonation progress.

\subsection{Data processing, ANN Architecture and Parameters}

In neural nets modelling, normalization of data is important to avoid early saturation within the hidden layer, which causes slower convergence (37). In addition, the operation is necessary in order to avoid scaling variables to zero thereby reducing their significance. Normalization could be binary or bipolar numbers depending on the transfer function adopted. The logistic sigmoid transfer function was used between the layers hence binary normalization was performed. Normalization was performed within each variable.

In this study, feed-forward back propagation was used for two optimization functions. Results obtained with Levenberg-Marquardt Backpropagation (LM), which is commonly used in ANN studies of different fields due to yielding a lower number of iterations, were used for comparison with the results obtained from an alternative function, Scaled Conjugate Gradient (SCG) suggested in this study.

The network contains three (input-hidden-output) layers with one hidden layer. The input layer represents the sources node, which receives signals from the external environment. Within this layer, 18 nodes (see Table 1.) were identified from factors influencing the progress of carbonation in concrete. Figure 1 illustrates the architecture of the proposed model. Results of the preliminary studies carried 


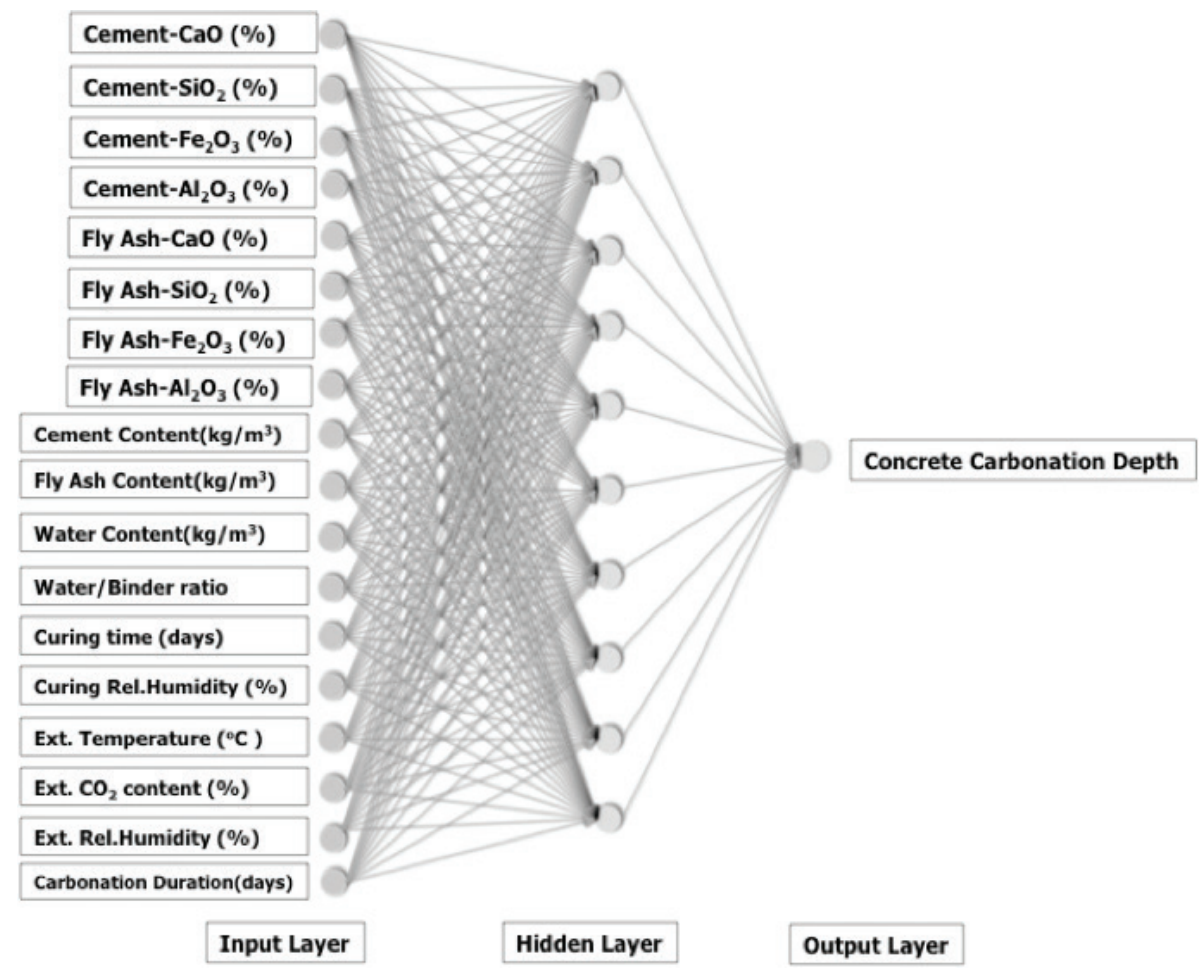

FIGURE 1. Architecture of the proposed model.

out indicated that 10 neurons were the optimized value for the hidden layer (8). Therefore, this hidden neuron value was kept constant in this study. The output layer has only one node, which is the depth of carbonation measured in concrete.

Three different learning schemes (LS) were adopted with training/testing distributions, as LS1 being 40:60; LS2 being 50:50; and LS3 being 60:40\% of the sample set. Hence, combinations of two training algorithms with three learning schemes with a constant hidden neuron value were studied with each optimization function (see Table 2). A MATLAB script, which has been uploaded to a public repository (38), was used to perform this analysis. Network training goal was selected as 20,000 iterations and mean square error (MSE) was aimed to reach the value of 0.001 . Holdout method of cross-validation was used to validate network performance. The adequacy of the proposed ANN models to predict the concrete carbonation depth effectively was studied by taking correlation coefficient $(\mathrm{R})$ and mean squared error (MSE) as a basis for measurement.

\subsection{Parametric Analysis on Proposed ANN Model to Study the Progress of Concrete Carbonation}

Parametric analysis study was made to verify the robustness and generalization ability of the proposed ANN architecture, in addition, to provide insights into the effect of selected key input parameters on the evolution of carbonation depth. The individual effects of selected key input parameters were studied systematically by running the model with a varying parameter of interest while keeping the other independent parameters constant. For instance, while an external parameter such as temperature, $\mathrm{CO}_{2}$ content or relative humidity (inputs 15-17) were being varied in order to investigate their effects on carbonation progress, the other concrete related parameters (inputs 1-14) were kept constant. On the other hand, in order to study the effect of other interdependent parameters, the dependency of the related parameter was also considered in order to ensure the consistency of the findings. For instance, in the case of variation of cement content $\left(\mathrm{kg} / \mathrm{m}^{3}\right)$, the water content $\left(\mathrm{kg} / \mathrm{m}^{3}\right)$ was also varied accordingly, in order to be able to keep a constant water/binder ratio. Similar precautions have been taken when a cement compound's composition (i.e. Cement's $\mathrm{CaO}$ or $\mathrm{SiO}_{2}$ content) were being varied to ensure reasonable contents for other cement compounds. For instance, considering the fact that the summation of all compounds' contents should never be more than $100 \%$; increasing the content of one compound while keeping the contents of other compounds constant would not be coherent. In order to ensure realistic combinations of cement compounds contents, a total of 12 real cement cases with varying compound content percentages were selected from the used dataset and parametric analyses were 
carried out on these data accordingly. In this way, the progress of carbonation depth due to the variation of the focused parameter was investigated. A detailed discussion of the obtained results and their comparison with the previous literature are presented in the following section.

\section{RESULTS AND DISCUSSIONS}

\subsection{Prediction efficiencies of the proposed models based on the correlation coefficient and mean squared error results:}

Results for correlation coefficient (R), mean squared error (MSE) and total network iteration for the two studied optimization functions are presented in Table 2. The number of iterations indicates how fast the results are provided by the network. The number of iterations to obtain the results were observed to be up to a maximum of 1581 , which was recorded to be yielded only within a minute. Since all networks yielded the results in less than a minute, which is not considered as critical compared to conventional civil engineering laboratory experiment durations, the number of iterations was not focused as determining criteria in order to choose an efficient network. Therefore, the discussion of results is based on mainly on the values of correlation coefficient (R) and mean squared error (MSE) obtained for each case.

It is observed from Table 2 that high $\mathrm{R}$ and low MSE values were obtained for all presented cases that indicate notable level accuracy of the model in general since even the lowest value was observed to be as high as 0.957 ; indicating more than $95 \%$ prediction accuracy.

It was observed that the correlation coefficient values yielded with both LM and SCG functions were very close to each other within each individual case The results presented in Table 2 also indicate that the carbonation depth prediction accuracies increase when training data set was increased from $40 \%$ to $60 \%$, since $\mathrm{R}$ values are observed to be with increased and MSE values are observed to be decreased. R-value increased up to 0.98 , for

TABLE 2. Results for R, MSE and number of iterations with proposed learning schemes

\begin{tabular}{lcccr}
\hline $\begin{array}{l}\text { Learning } \\
\text { Scheme }\end{array}$ & $\begin{array}{c}\text { Optimization } \\
\text { Method }\end{array}$ & R & MSE & iter. \\
\hline $\mathbf{4 0 : 6 0}$ & SCG & 0.964 & 0.0039 & 467 \\
& LM & 0.957 & 0.0045 & 40 \\
$\mathbf{5 0 : 5 0}$ & SCG & 0.975 & 0.0026 & 789 \\
& LM & 0.976 & 0.0026 & 44 \\
$\mathbf{6 0 : 4 0}$ & SCG & 0.983 & 0.0019 & 1581 \\
& LM & 0.985 & 0.0016 & 41 \\
\hline
\end{tabular}

both optimization functions in the case of learning scheme-3 where 60:40 training to testing data distribution was employed. Therefore, the second part of this work, in which the influence of key input parameters on the progress of carbonation problem in concrete will be studied, the combination of learning scheme- 3 conditions, with 60:40 train:test data distribution selection. It has been observed that the majority of the studies in the related literature employ LM function without reporting any major justification $(8,11,39)$. As the $\mathrm{R}$ values yielded with both LM and SCG are observed to be almost equal in Table 2, SCG has been proposed to be used in the second stage of this study (i.e. parametric analysis section) in order to emphasize the possibility of not using LM as kind of a "default" selection, while still maintaining high accuracy levels.

Training and testing subset network performance and the respective regression evolution for this best case for Scaled Conjugate Gradient (SCG) function are presented in Figures 2a and 2b, respectively.

A partially comparable study was previously presented by Kellouche et al. (2017) (40); in which only six input parameters were used in a three-layer neural net having 8 neurons in the hidden layer. Furthermore, previous works done on the concrete carbonation by using ANN approach for prediction (9-11) are observed to have limited number of experimental data, which is known to negatively affect the reliability of the predictions' accuracy. Beside the use of a significantly increased number of experimental data, this study presents a more detailed investigation on the efficiency of alternative ANN models when compared to other studies in the related literature, with results reported for different learning schemes. In addition to these, with the innovative inclusion of concrete components' compositional

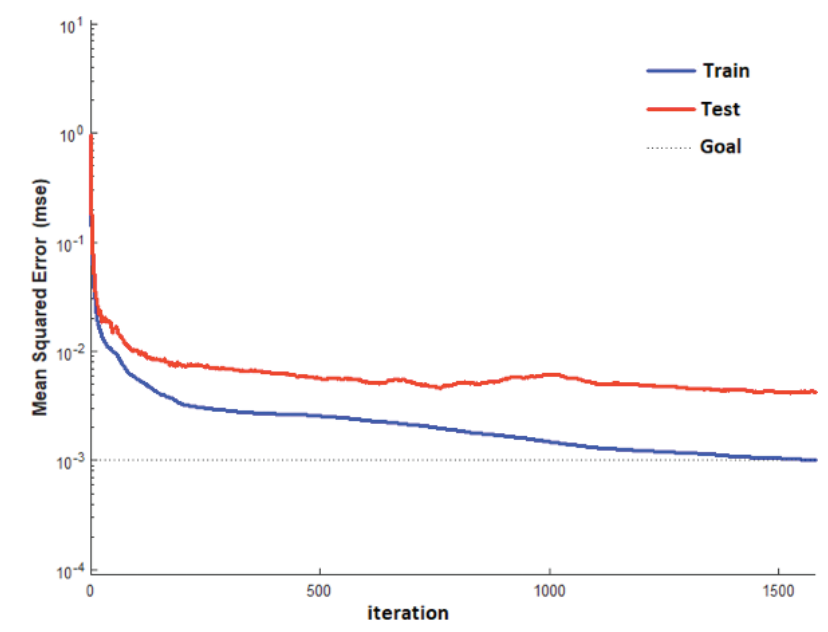

FIGURE 2. The best prediction case using SCG with 60:40 data distribution. Part-a (left) The evolution of MSE Part-b (right) Regression values for measured vs. predicted carbonation depth 
information as input parameters, which is not considered in similar works in the related literature before, this study provides the grounds for exploring the possibilities of significantly improved prediction models for carbonation depth in concrete, which might then be employed for successful investigations on the progress of carbonation problem with varying conditions, providing further understanding on the fundamentals of this critical durability issue in a systematical and accelerated way.

\subsection{Parametric analysis results studying the progress of carbonation in concrete with the effect of selected major input parameters on the carbonation depth}

After the determination of the best-case combination of the model yielding highest prediction accuracy for the use of the group of Scaled Conjugate Gradient Backpropagation, the model was further employed to study the progress of carbonation depth in concrete with the individual influence of each one of eight selected input parameters. The study focused only on the effects of $\mathrm{CO}_{2}$ content, external temperature and humidity, w/c ratio of concrete, fly ash inclusion, the cement content of concrete, as well as the contents of two well-known compounds of cement, that are $\mathrm{CaO}$ and $\mathrm{SiO}$, with the intention of providing information primarily on the presented prominent parameters at this stage. Results obtained within this parametric sensitivity study are presented in Fig 3-10.

Figure 3 demonstrates the effect of varying $\mathrm{CaO}$ content of cement on the concrete carbonation depth at the ages of $90,180,365,545$ and 730 days.
For generating this parametric analysis; a constant cement content of $300 \mathrm{~kg} / \mathrm{m}^{3}$ was considered with no fly ash addition and with a constant w/c ratio of 0.51 . For the external parameters such temperature, relative humidity and $\mathrm{CO}_{2}$ content, values of realistic cases such as $20{ }^{\circ} \mathrm{C}, 65 \%$ and $0.03 \%$ were considered, respectively. Carbonation depth is clearly observed to be increasing with increasing concrete age, which is in accordance with the conventional civil engineering experience and with previously published experimental works $(12,13,15-24)$, indicating the consistency of the simulation. Increasing $\mathrm{CaO}$ content is observed to lead to an increase in depth of carbonation for all ages. The observed increase of carbonation depth with increasing $\mathrm{CaO}$ could be described with polynomial trends for the cases of 180 and 730 days (as two examples for earlier and later ages), which yielded very high $\mathrm{R}^{2}$ values such as 0.99 in both cases. The evolution of the observed increase and the trend lines could not be directly compared to the results of previous studies, since the effect of cement $\mathrm{CaO}$ on the concrete carbonation has not been presented in a comparable manner in the related previous literature. It was also observed that, for cement having relatively lower $\mathrm{CaO}$, the effect of increasing sample's age (i.e. longer exposure to carbonation) is more evident than for the cement having higher $\mathrm{CaO}$ (see Figure 3). Additionally, concrete with higher $\mathrm{CaO}$ cement contents are observed to yield much higher carbonation depths even in the earlier ages. A similar remark has also been made by Arandigoyen et al. (2006) (41) who studied carbonation of mortars with the addition of lime that yielded an increased total amount of $\mathrm{CaO}$ and hence, increased amount of $\mathrm{CH}$ in the

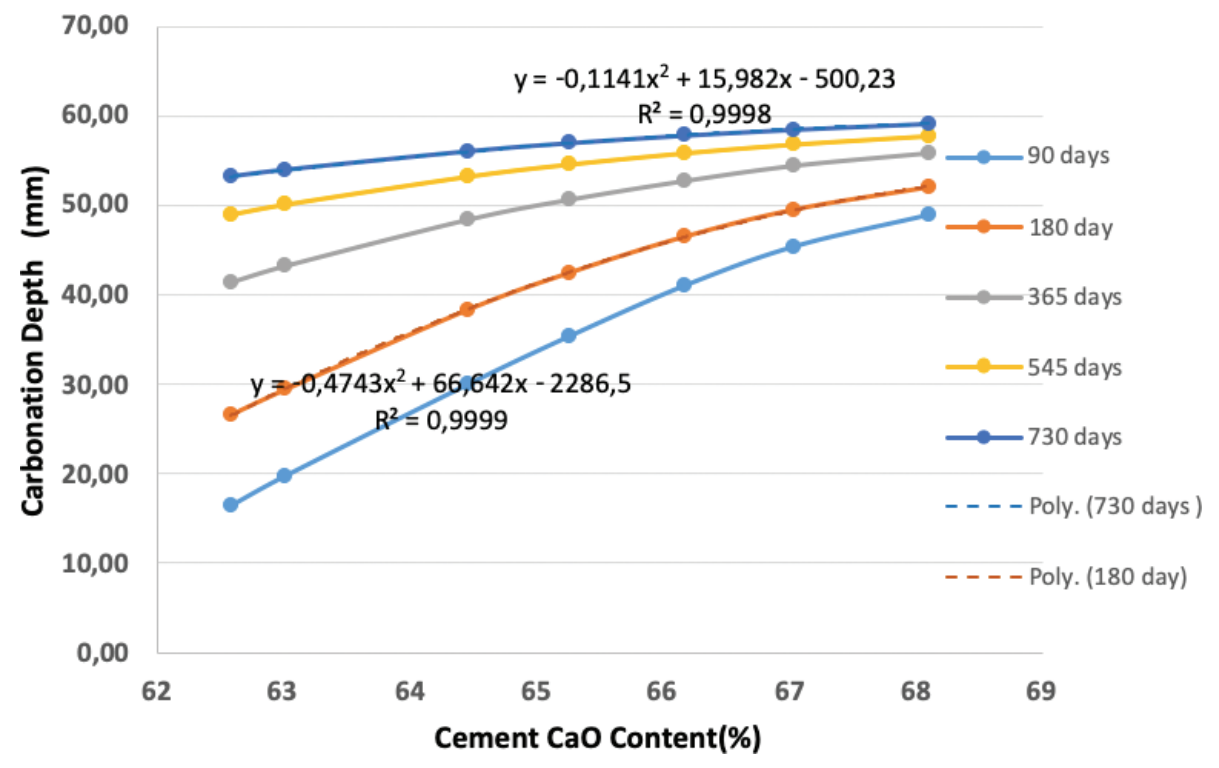

Figure 3. Effect of cement $\mathrm{CaO}$ content on carbonation. 
mix. The observed increase in carbonation depth might be related to the increased availability of portlandite $(\mathrm{CH})$ in concrete mixes manufactured with cement having high $\mathrm{CaO}$ contents, that can be available for carbonation Further experimental studies focusing on these mechanisms could be beneficial, since this observation might be potentially critical for understanding the critical threshold of $\mathrm{CaO}$ contents of cements that are to be considered in a certain concrete mix design, so that a certain tolerated carbonation depth is not exceeded.

Similarly, Figure 4 demonstrates the effect of varying $\mathrm{SiO}_{2}$ content of cement on the concrete carbonation depth at the ages of $90,180,365,545$ and 730 days. While varying the $\mathrm{SiO}_{2}$ content of cement within the range shown in Figure 4, the other concrete and environmental parameters were set in the same values as previously defined for Figure 3. Figure 4 also demonstrates that carbonation depth increases with increasing sample age, as observed in Figure 3. Carbonation depth was observed to have increased the with an increase in $\mathrm{SiO}_{2}$ content. $\mathrm{SiO}_{2}$ containing clinker compounds in cement are known to be likely to contribute to C-S-H formation in concrete, that is also known to be prone to the action of carbonation generally after the carbonation of $\mathrm{CH}$ (26). This could be a potential reason for the observed carbonation depth increase with increasing $\mathrm{SiO}_{2}$ content, that should be further verified with additional studies focusing on cement's $\mathrm{SiO}_{2}$ content. The increase in carbonation depth is observed to start ceasing beyond a $\mathrm{SiO}_{2}$ content value of $24 \%$. The trend of the observed progress of carbonation depth could be described with polynomial fits for the cases of 180 and 730 days, with $\mathrm{R}^{2}$ values higher than 0.90 in cases of both of these ages. The evolution of the observed increase and the trend lines could not be compared directly with the previous literature since no other comparable study on the effect of cement $\mathrm{SiO}_{2}$ on carbonation could be identified in the previous literature.

Cement types are mainly classified according to their chemical compositions. Both Silva et al. (2014) (36) and Elmoaty et al. (2018) (42) emphasize the importance of cement types in the determination of final carbonation depth. Some of the studies in the literature, have considered only the cement content $\left(\mathrm{kg} / \mathrm{m}^{3}\right)$, practically ignoring the type of cement to be added $(11,40)$. Some other studies presented concrete carbonation results varying based on only certain cement types that were specified in those particular studies (42) in a categorical manner, and their models cannot be employed directly for other cases where another cement could be used. The model proposed in this study is capable of considering the employment of different types of cement more extensively; since, the compound compositions are directly taken into consideration, allowing the inclusion of numerous possibilities.

Figure 5 and 6 illustrate the effect of increasing cement content and the effect of increasing fly ash inclusion, respectively, on concrete carbonation depth at the ages of $90,180,365,545$ and 730 days. For generating these parametric analyses; constant values for environmental parameters that are $20^{\circ} \mathrm{C}$ temperature, $65 \%$ relative humidity and $0.03 \% \mathrm{CO}_{2}$ content were considered. For figure 5; cement content was varied between $260-580 \mathrm{~kg} / \mathrm{m}^{3}$ for a concrete

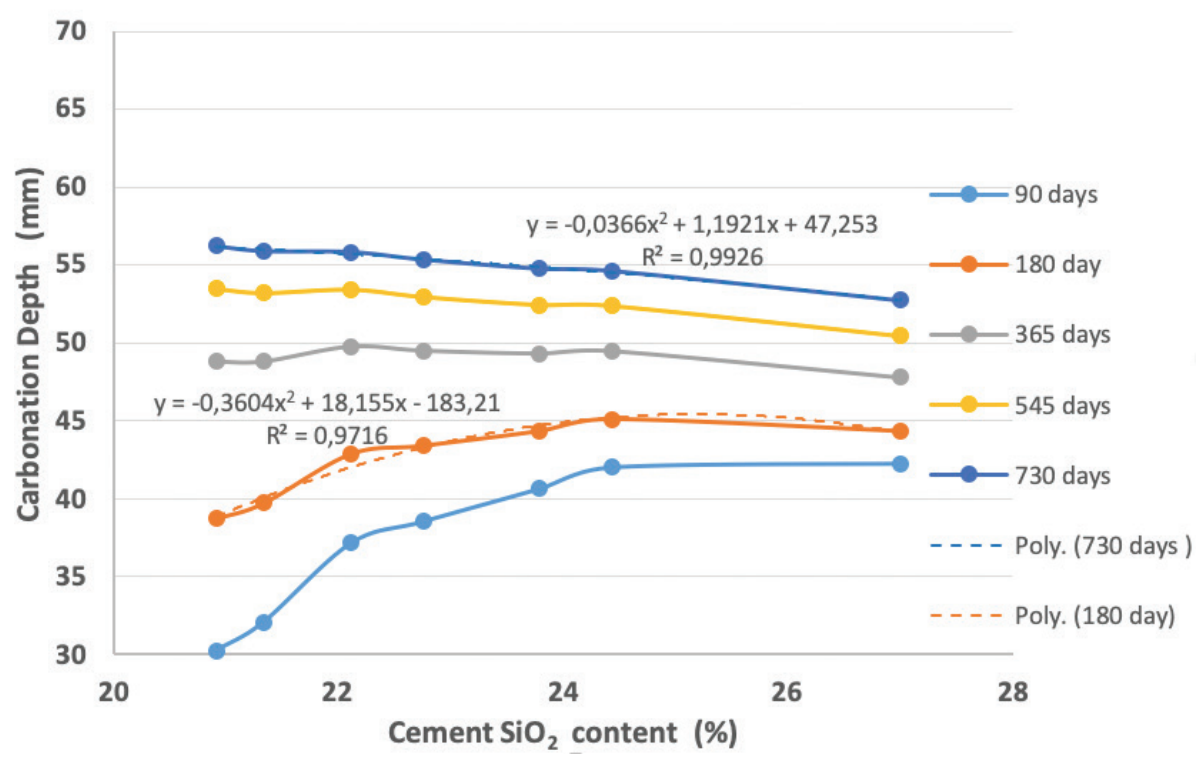

Figure 4. Effect of cement $\mathrm{CaO}$ content on carbonation. 


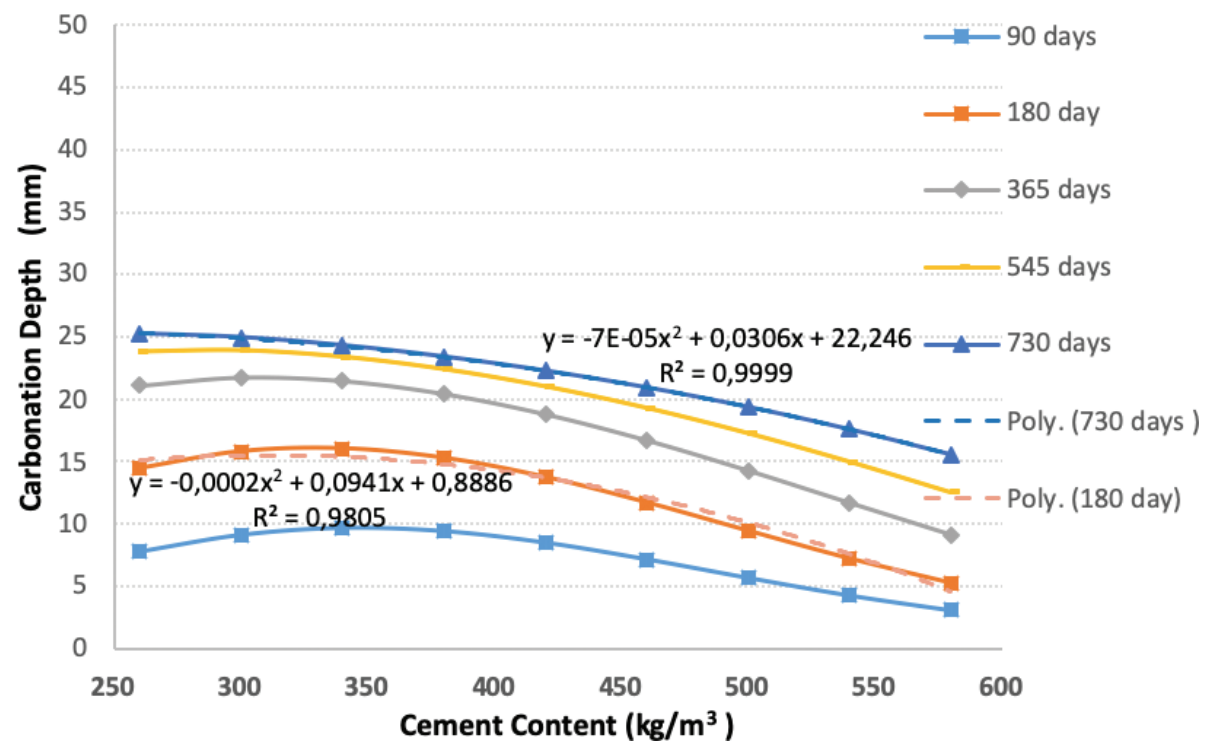

FIGURE 5. Effect of cement content on carbonation depth.

mix of a constant w/c ratio of 0.51 and with no fly ash addition. For figure 6; cement content and w/c ratio were kept constant at values $300 \mathrm{~kg} / \mathrm{m}^{3}$ and 0.51 , respectively, where fly ash inclusion was varied between $0-70 \%$.

Figure 5 shows that there was decrease in carbonation depth with increasing cement content per meter cube of concrete, for all ages. These decreasing behavior of carbonation depth values estimated for 180 and 730 days in this study could be described with polynomial trend lines with relatively high $\mathrm{R}^{2}$ values as demonstrated in the figure. This observed decreasing effect could possibly be due to the increasing density of concrete as the cement content increases. Hence, the ingress of $\mathrm{CO}_{2}$ into concrete to initiate carbonation becomes less in concrete mixes with higher densities (1). These findings are also in accordance with the previous literature (40). Kazts et al. (43) also has discussed the effect of increasing cement content on the progress of carbonation, in terms of carbonation "coefficient" rather than the determined "depth"; hence the reported results could not be directly compared with the values obtained in this study. In their experimental

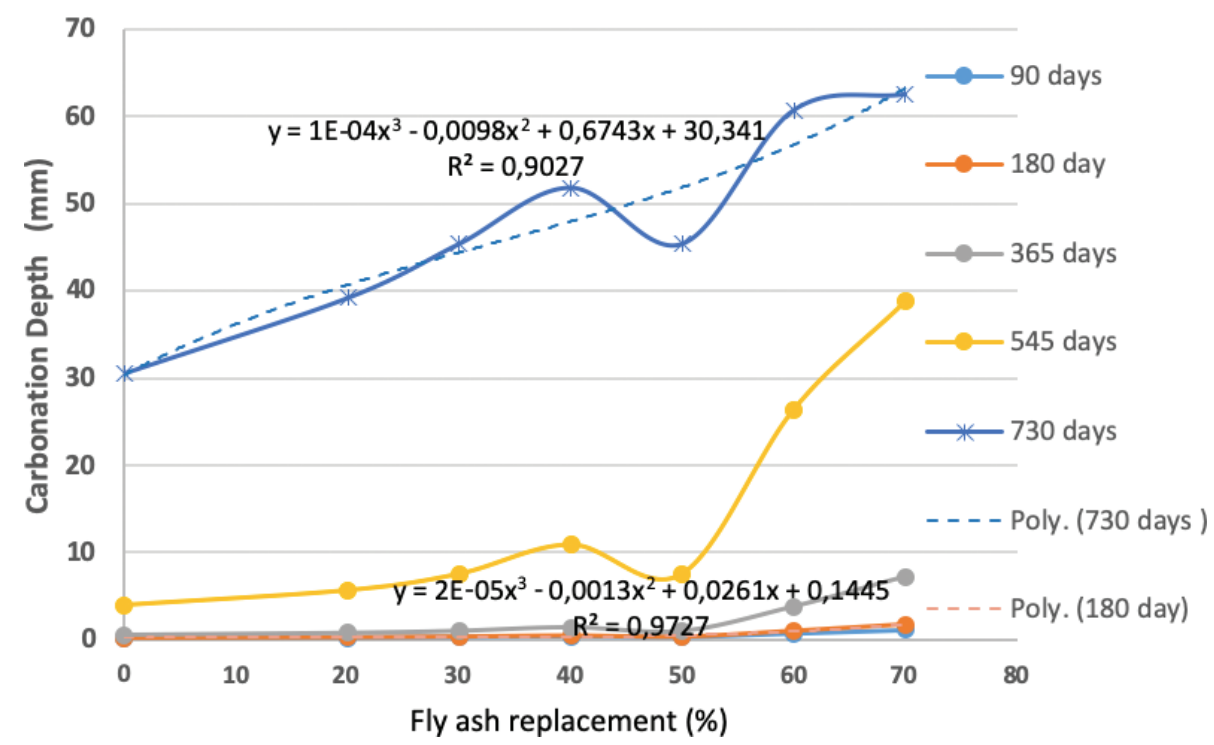

FIGURE 6. Effect of FA content on carbonation depth. 
study, Elmoaty et al. (42) reported a 4 mm decrease in carbonation depth when cement content was increased from 350 to $450 \mathrm{~kg} / \mathrm{m}^{3}$. In this study, when the values reported in figure 5 for the increase in cement content from 340 to $460 \mathrm{~kg} / \mathrm{m}^{3}$, an average of $4.02 \mathrm{~mm}$ decrease in carbonation depth could be observed; indicating consistency of the tendencies and values predicted with the model proposed in this study with the findings of an independent experimental work.

Figure 6 illustrates that the use of high volume fly ash increased the susceptibility of concrete to carbonation attack. This finding is in accordance with experimental results in the (44). In this figure, the effect of fly ash addition becomes more evident primarily at later ages such as 545 and 730 days. In general, an increase in the fly ash addition is observed to yield an increased carbonation depth as suggested in the previous literature (40). This general trend has been steadily observed except for the specific value of $50 \%$ fly ash replacement yielding a relatively lower value of carbonation depth in this study. Further studies with different set of constant values for input parameters at a fly ash content of $50 \%$, would be needed in order to provide more insights on this specific tendency observed at this particular fly ash content value. for In their experimental study, Hongzhou and Kasami (2013) (45) have investigated the increase in the contents of three types of fly ashes on concrete carbonation depth; and a significant increase in the depth of carbonation with the increase in fly ash content has been reported in their study as well. Hongzhou and Kasami (2013) (45) also emphasized the effect of fly ash type, which was intended to be covered by considering the fly ash compounds compositions as individual influencing input parameters within this study, in addition to the its total content. Trend lines fitted to these behavior tendencies observed at different ages in figure 6 could not be compared directly to previous studies, due to unavailability of necessary information in the literature in a comparable manner. The possibility of quantification of carbonation depth to be expected in concrete with fly ash addition under specified conditions accurately, would serve to the improvement of studies dealing with the determination of performance of structures during their service lives.

Figures 7 and 8 demonstrate the effect of varying $\mathrm{CO}_{2}$ content and varying temperature respectively, on the concrete carbonation depth at the ages of $90,180,365,545$ and 730 days. A total of twelve $\mathrm{CO}_{2}$ values were used in the generation of the graph presented in Figure 7, which are varying between $0,03 \%$ (i.e. equivalent to the natural value), and $3.03 \%$ (i.e. equivalent to hundred times more of the natural value). Cement content and w/b ratio were kept constant as $300 \mathrm{~kg} / \mathrm{m}^{3}$ and 0.51 , for the case of no fly ash addition, the relative humidity was kept at $65 \%$, at $20{ }^{\circ} \mathrm{C}$ temperature, as in other parametric analyses described above. A slight but steady increase in carbonation depth was observed with the increase in $\mathrm{CO}_{2}$ content within the proposed range. Results presented in the previous literature also suggests an increase in the carbonation depth with increased $\mathrm{CO}_{2}$ content (40). As it can be noted from the graph, the points indicating carbonation depth values for the first eight $\mathrm{CO}_{2}$ contents ranging between $0.030-0.18 \%$ are very close, in fact yielding a variation of carbonation depth only

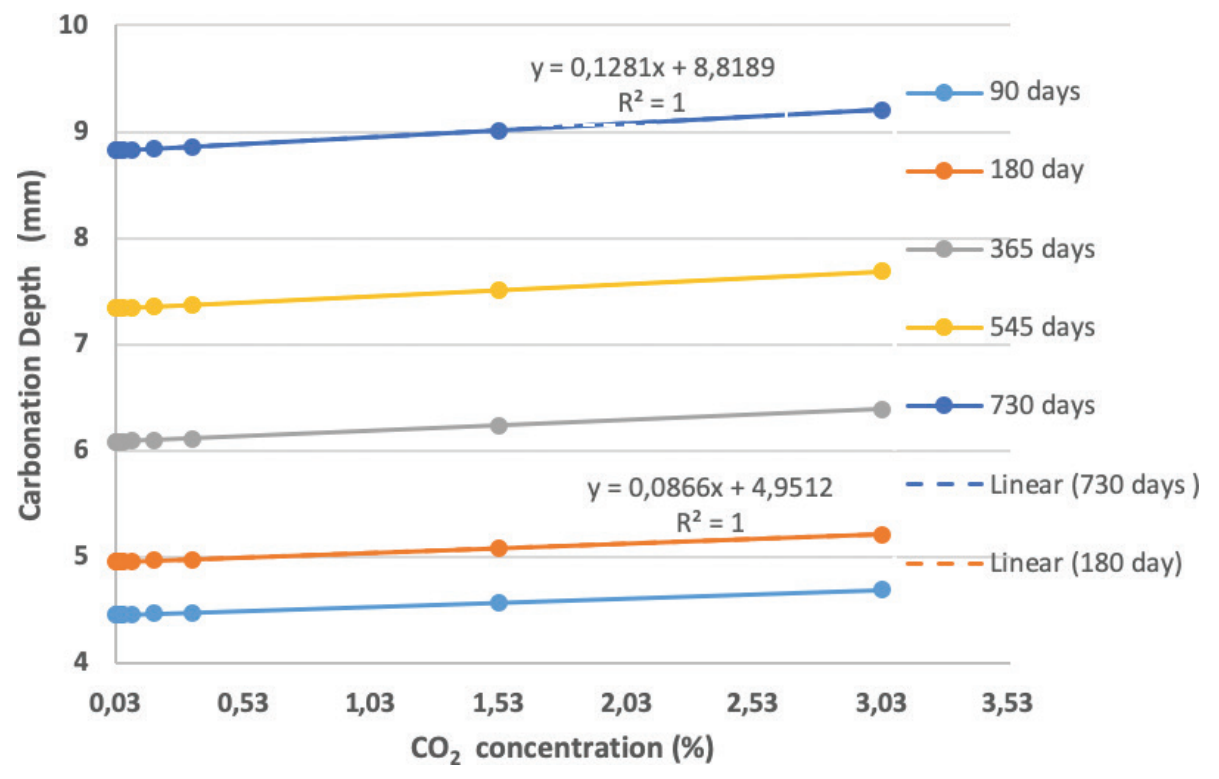

FIGURE 7. Effect of $\mathrm{CO}_{2}$ content on carbonation depth. 


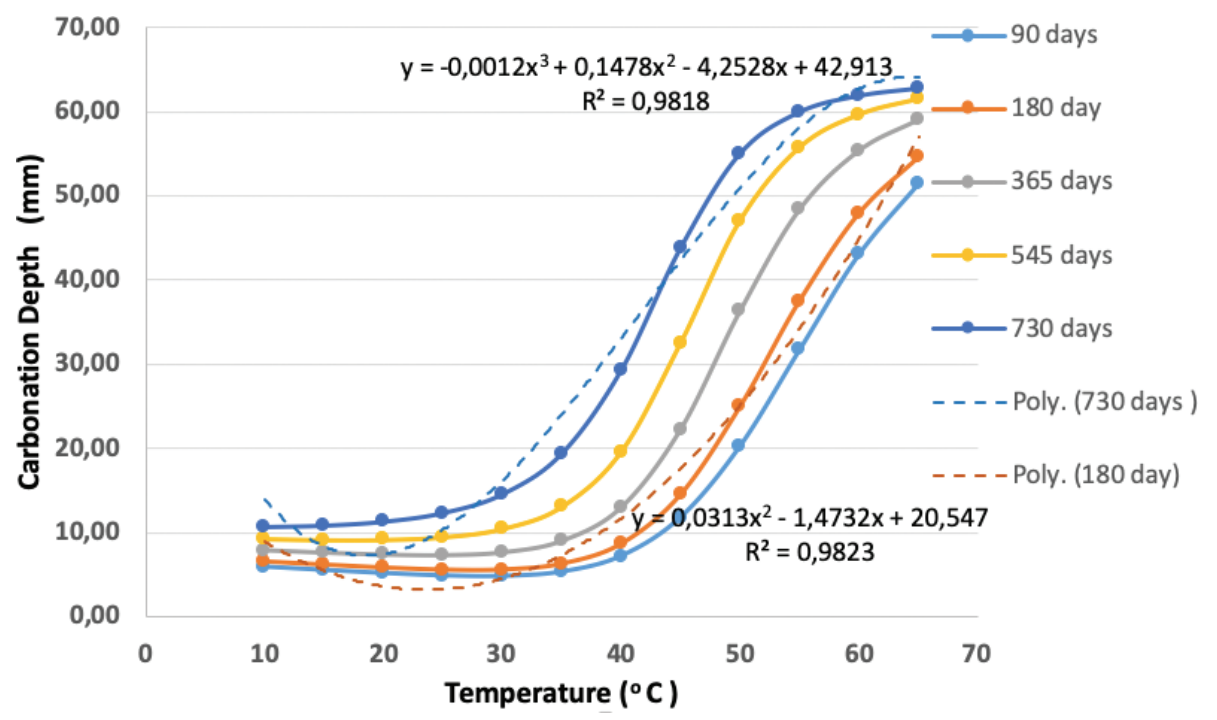

FIGURE 8. Effect of temperature on carbonation depth.

within $0.1-0.2 \mathrm{~mm}$. In relative terms, it is observed that the variation in the carbonation depth recorded for $\mathrm{CO}_{2}$ beyond $0.18 \%$ (i.e. last three data points plotted for each age) is more appreciable than the variation in the carbonation depth for the $\mathrm{CO}_{2}$ content range lower than $0.18 \%$. It is observed that the increasing tendency of carbonation depth could be represented by a linear trend line fits for the given range of $\mathrm{CO}_{2}$ content.

According to these obtained results, the carbonation values that are presented for the entire $\mathrm{CO}_{2}$ content range of Figure 7 are observed to be relatively less remarkable when compared with the carbonation depth variations observed with the changes in other parameters, such as in the case of temperature variation (Fig 8), in which the recorded carbonation depth could increase even beyond $50 \mathrm{~mm}$. These findings may imply that; even though the presence of $\mathrm{CO}_{2}$ is essential for the occurrence of carbonation, the $\mathrm{CO}_{2}$ content itself is not the primary parameter defining the severity of the extent of the carbonation progress. Rather, a combination of other parameters' critical values is observed to be determining the significantly higher values of carbonation depth.

Figure 8 illustrates the results of the parametric analysis generated for temperature varying between $10-65^{\circ} \mathrm{C}$. Numerous regions in the world are known to experience apparent temperature values as high as 40 degrees Celsius. In some middle east countries such as, Iraq and Kuwait, the temperature is reported to go beyond even $53^{\circ} \mathrm{C}(46)$, which makes the consideration of concrete carbonation at high temperatures noteworthy. Another reason for the interest in studying carbonation in relatively high temperatures is due to the fact that high temperatures are used as an important experimental condition in "accelerated" carbonation tests. Hence, the selected range of temperature was decided to be used in the parametric analysis. For this analysis in figure 6 , the constant cement content of $300 \mathrm{~kg} / \mathrm{m}^{3}$, $0.51 \mathrm{w} / \mathrm{ratio}, 65 \%$ relative humidity and $0.03 \% \mathrm{CO}_{2}$ content values were used. In Figure 8, the increase in temperature is observed to yield in increased carbonation depth. This behavior could be due to the increased solubility of $\mathrm{CO}_{2}$ gas that is expected at higher temperatures, facilitating the carbonation action in two phases: diffusion of $\mathrm{CO}_{2}$ and reduction in moisture content which enables gaseous diffusion and increased diffusivity, as also explained in detail in the previous literature (1). The increasing carbonation depth tendencies in figure 8 plotted for each age in this study could be fitted with polynomial trend lines of different degrees, depending on the age, when temperature was considered up to $65^{\circ} \mathrm{C}$. Liu et al. (32) has reported linear behavior of temperature effect on increasing carbonation depth in their study in which temperature value was extended only up to $30^{\circ} \mathrm{C}$. Hence, extending temperature values to include the cases of accelerated carbonation as done in this study, provided further insights on the changing manner in the progress of carbonation in concrete, which could be critical consideration for researchers aiming to quantify carbonation depth in distinctive studies.

Figures 9 and 10 demonstrate the effect of varying relative humidity $(\mathrm{RH})$ and water/binder ratio respectively, on the concrete carbonation depth at the ages of $90,180,365,545$ and 730 days. In Figure 9, up to $75 \%$ of $\mathrm{RH}$, the carbonation depth increases as the RH increases. Further increase in $\mathrm{RH}$ as observed to cause a decrease in the depth carbonation. This trend is observed to become more evident mainly at later ages of the concrete. Experimental studies in the literature (32) describe 


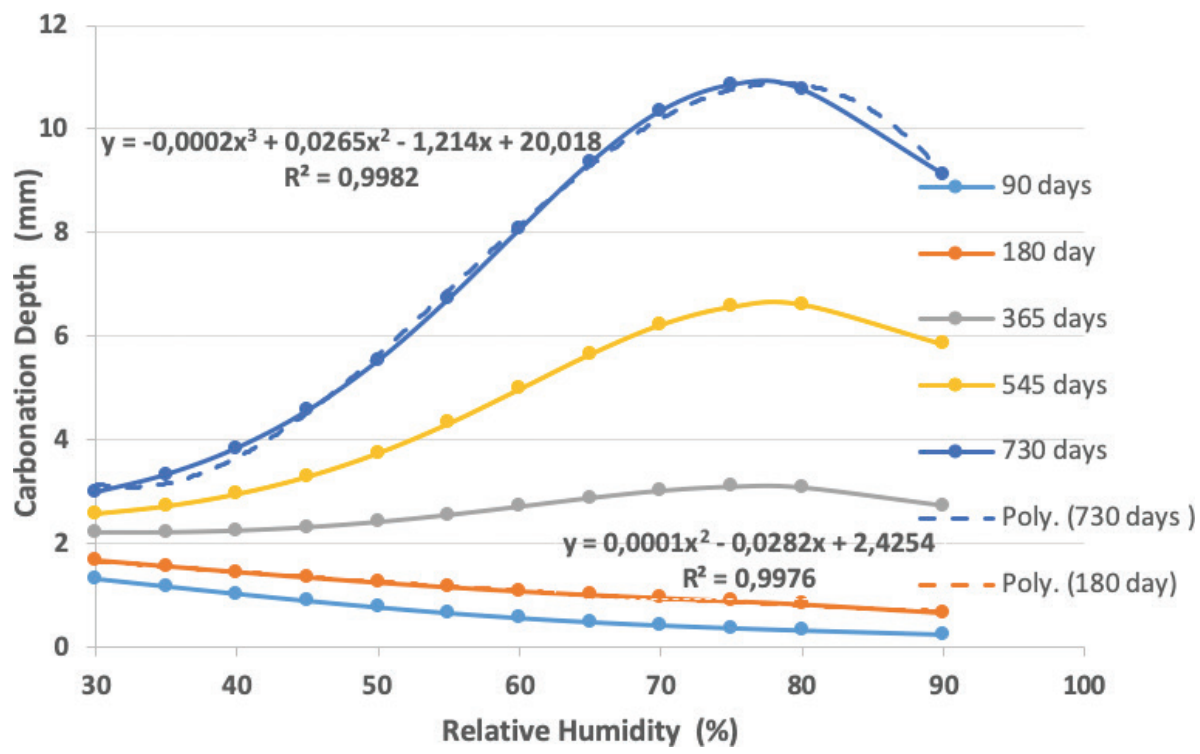

FIGURE 9. Effect of relative humidity on carbonation.

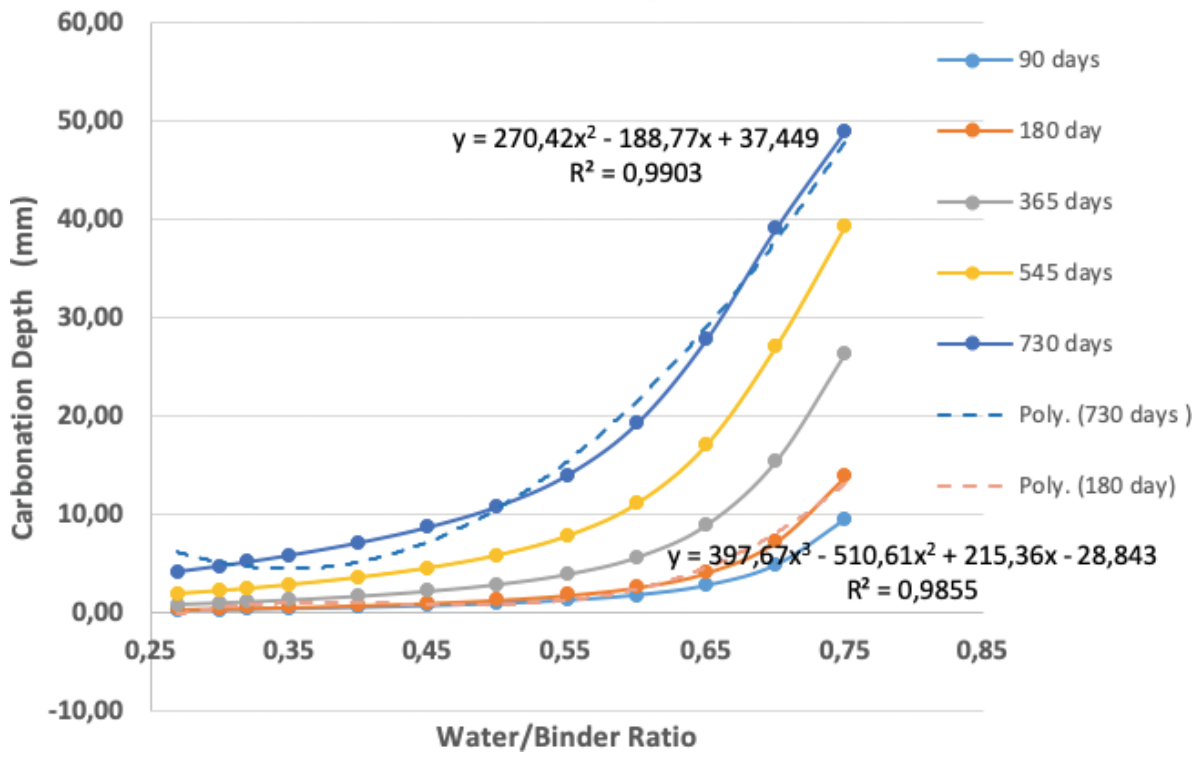

FIGURE 10. Effect of water/binder ratio on carbonation.

a similar tendency that they observed and suggested that it might be experienced due to saturation in the pore spaces within the microstructure. The RH value that yielded the highest carbonation depth is observed to be around $75 \%$, which is close to the value reported in (40). Polynomial trend lines of second and third degrees were used for defining the tendencies of carbonation depth progress in 180 and 730 days, respectively. In their experimental study, Liu et al. (2019) (32) also reports a polynomial tendency of carbonation depth increase with around $70 \%$ relative humidity being the value yielding maximum carbonation depth. Hence, the model proposed in this study is observed to provide reliable information on the carbonation depth evolution with respected to relative humidity, since the results obtained are greatly in harmony with independent experimental concrete carbonation studies.

Fig 10 shows that an increase in the water/binder ratio yields in an increase in the carbonation depth of concrete. The increase in carbonation depth could be defined with a polynomial trend as shown in figure 10 in this study. Katz et al. (43) also reports 
a very clear increase in concrete carbonation with the increasing w/c ratio, without suggesting a fitted trend for the increase that they have observed. Other concrete carbonation experimental studies (47) also report increasing concrete carbonation as a result of increased water/cement ratios used in the concrete mixes. Increased water/binder ratio is known to yield increased porosity and permeability; hence, carbonation attack may progress more through the concrete.

In this study, primarily the influence of eight selected input parameters on the progress of concrete carbonation has been presented in order to investigate the feasibility and the efficiency of the proposed carbonation depth prediction model to be employed for further understanding the fundamentals of this concrete problem. Different than other previously suggested ANN models, the compositional information of both cement and potentially added fly ash have also been considered in this study, enabling to use the model by differentiating between different cement types that could be used in real cases. High overall prediction accuracy of the proposed model, as well as the compliance of the findings of generated parametric analyses with other reported independent experimental results in the literature, imply the possibility of successful employment of the proposed ANN model to investigate the progress of carbonation problem in concrete under numerous combinations of influencing parameters in an efficient way.

\section{CONCLUSIONS AND RECOMMENDATIONS FOR FUTURE STUDIES}

In this study, a novel ANN model including cement and fly ash compound composition as influencing input parameters was used by employing two different optimization functions. Relatively a large data set acquired systematically from the literature was used in order to ensure the representability and the reliability of the calculations carried out. An increase in training dataset from $40 \%$ to $60 \%$, improves the network prediction performance both for the aspects of $\mathrm{R}$ and MSE values, with both models using Scaled Conjugate Gradient (SCG) and Levenberg-Marquardt (LM) functions. Significantly high $\mathrm{R}$ values, such as more than 0.98 , together with significantly low MSE values obtained in this study for both SCG and LM functions, strongly suggest that the model with proposed architecture can be efficiently used for the prediction of carbonation depth in concrete. The insignificant difference between of LM's and SCG's accuracies, indicates the convenience of the use of alternative learning algorithms such as SCG in these fields of studies, since the level accuracy is a more critical efficiency criterion than the speed of convergence is for civil engineering applications.
Parametric studies carried out after the verification of the prediction efficiency of the proposed model provided noteworthy findings. Increasing cement's $\mathrm{CaO}$ content of has been observed to yield an increasing tendency of carbonation depth of concrete. Moreover, concrete mixes with relatively higher $\mathrm{CaO}$ contents were observed to yield significantly higher carbonation depths even in the earlier ages. An increase in the cement's $\mathrm{SiO}_{2}$ content has also been observed to an increase in concrete carbonation. This increase in carbonation depth was observed to start ceasing beyond a $\mathrm{SiO}_{2}$ content value of $24 \%$ in this study. Further investigations on binders' compounds compositions have the potential to provide an improved understanding on the characteristics and the types of binders that should be sought after under critical carbonation exposure conditions. Carbonation depth in concrete was observed to be decreasing with increasing cement content for all ages. On the other hand, an increasing fly ash content was observed to increase the progress of carbonation. The effect of fly ash addition became more evident primarily at later ages such as 545 and 730 days.

The results obtained by the parametric analyses carried out with the proposed ANN model also showed that an increase in $\mathrm{CO}_{2}$ content within the range from $0.03 \%$ (i.e. natural value) up to $3 \%$ (i.e. hundred times more than the natural $\mathrm{CO}_{2}$ content), yielded a steady linear increase in carbonation depth of concrete. The actual depth of carbonation in millimeters yielded in this studied $\mathrm{CO}_{2}$ content range was observed to be relatively less remarkable when compared with the carbonation depth values yielded with during the parametric analyses of other inputs. Therefore, it is suggested that even though the presence of $\mathrm{CO}_{2}$ is essential for the occurrence of carbonation, the severity of the carbonation progress in concrete is primarily defined by a combination of other considered parameters' critical values, rather than solely being due to an increased $\mathrm{CO}_{2}$ content. On the other hand, the variations in other external exposure conditions such as temperature, has been observed to yield a relatively much higher increase in the depth of carbonation in concrete. This increase in carbonation depth was observed to be with changing tendencies, when the range of temperature was extended to include higher values. It was also observed that an increase in the external relative humidity up to the value of $75 \%$, yielded increased depths of concrete carbonation. However, when this value was exceeded a decrease in the progress of carbonation was experienced. It was also observed that concrete mixes having higher water/ binder ratios were yielding an increased level of carbonation, as expected.

In addition to the obtained high general prediction accuracy, the high level of compliance of the findings obtained by the model on carbonation 
progress under the selected prominent parameters with the results reported by independent previous experimental studies in the literature, was interpreted as an indication of the proposed model's potential success in investigating concrete carbonation cases with varying combinations of parameter values in a reliable way. Hence, the employed model has the potential to serve as an efficient tool to study carbonation problem in concrete, providing further insights on the fundamentals of this critical durability problem without using any elaborated, time and resources-consuming laboratory experiments

Further studies should be carried out in order to provide understanding on the remaining input parameters considered in the proposed model in this study. Also, the studies should be extended to include concrete parameters such as aggregate properties, loss on ignition of binders, as well as the cases of concrete mixes prepared with chemical admixture inclusions. Further improvement of the intelligent studies on concrete carbonation might be explored in the future studies by employing other promising methods such as deep learning and heuristic algorithms. Moreover, a detailed set of statistical studies that could be carried out in parallel with the presented ANN study, is expected to provide an understanding of interrelations of all parameters considered in an enhanced way.

\section{REFERENCES}

1. Houst, Y.F. (1996) The role of moisture in the carbonation of cementitious materials. Int. J. Restor. Build. Monum. 2 , 49-66.

2. Castellote, M.; Andrade, C.; Turrillas, X.; Campo, J.; Cuello, G.J. (2008) Accelerated carbonation of cement pastes in situ monitored by neutron diffraction. Cem. Concr. Res. 38[12], 1365-1373. https://doi.org/10.1016/j. cemconres.2008.07.002

3. Shamsad, A. (2003) Reinforcement corrosion in concrete structures, its monitoring and service life prediction-a review. Cem. Concr. Compos. 25[4-5], 459-471. https://doi. org/10.1016/S0958-9465(02)00086-0

4. Huet, B.; L'Hostis, V.; Miserque, F.; Idrissi, H. (2005) Electrochemical behavior of mild steel in concrete: Influence of $\mathrm{pH}$ and carbonate content of concrete pore solution. Electrochim. Acta. 51[1], 172-180. https://doi. org/10.1016/j.electacta.2005.04.014

5. Malami, S.I.; Akpinar, P.; Lawan, M.M. (2018) Preliminary investigation of carbonation problem progress in concrete buildings of north Cyprus. MATEC Web Conf. 20306007. https://doi.org/10.1051/matecconf/201820306007

6. Khashman, A.; Akpinar, P. (2017) Non-destructive prediction of concrete compressive strength using neural networks. Procedia. Comput. Sci. 108, 2358-2362. https://doi. org/10.1016/J.PROCS.2017.05.039

7. Khashman, A. (2010) Neural networks for credit risk evaluation: Investigation of different neural models and learning schemes. Expert. Syst. Appl. 37[9], 6233-6239. https:// doi.org/10.1016/j.eswa.2010.02.101

8. Akpinar, P.; Uwanuakwa, I.D. (2016) Intelligent prediction of concrete carbonation depth using neural networks. Bull. Transilv. Univ. Braşov. Se.r III Math. Phys. 9[2], 99-108.

9. Kwon, S.-J.; Song, H.-W. (2010) Analysis of carbonation behavior in concrete using neural network algorithm and carbonation modeling. Cem. Concr. Res. 40[1], 119-127. https://doi.org/10.1016/j.cemconres.2009.08.022
10. Lu, C.; Liu, R. (2009) Predicting carbonation depth of prestressed concrete under different stress states using artificial neural network. Adv Artif Neural Syst. 20091-8. https://doi.org/10.1155/2009/193139

11. Taffese, W.Z.; Sistonen, E.; Puttonen, J. (2015) CaPrM: Carbonation prediction model for reinforced concrete using machine learning methods. Constr. Build. Mater. 100, 70-82. https://doi.org/10.1016/j.conbuildmat.2015.09.058

12. Villain, G.; Thiery, M.; Platret, G. (2007) Measurement methods of carbonation profiles in concrete: Thermogravimetry, chemical analysis and gammadensimetry. Cem. Concr. Res. 37[8], 1182-1192. https://doi.org/10.1016/j.cemconres. 2007.04.015

13. Kari, O.P.; Puttonen, J.; Skantz, E. (2014) Reactive transport modelling of long-term carbonation. Cem. Concr. Compos. 5242-53. https://doi.org/10.1016/j.cemconcomp. 2014.05.003

14. Saetta, A. V.; Vitaliani, R. V. (2005) Experimental investigation and numerical modeling of carbonation process in reinforced concrete structures: Part II. Practical applications. Cem. Concr. Res. 35[5], 958-967. https://doi.org/ 10.1016/j.cemconres.2004.06.023

15. Chang, C.F.; Chen, J.W. (2006) The experimental investigation of concrete carbonation depth. Cem. Concr. Res. 36[9], 1760-1767. https://doi.org/10.1016/j.cemconres.2004.07.025

16. Cui, H; Tang, W; Liu, W; Dong, Z; Xing, F. (2015) Experimental study on effects of $\mathrm{CO} 2$ concentrations on concrete carbonation and diffusion mechanisms. Constr. Build. Mater. 93, 522-527. https://doi.org/10.1016/j.conbuildmat.2015.06.007

17. Jiang, L.; Lin, B.; Cai, Y. (2000) A model for predicting carbonation of high-volume fly ash concrete. Cem. Concr. Res. 30[5], 699-702. https://doi.org/10.1016/S00088846(00)00227-1

18. Balayssac, J.P.; Détriché, C.H.; Grandet, J. (1995) Effects of curing upon carbonation of concrete. Constr. Build. Mater. 9[2], 91-95. https://doi.org/10.1016/0950-0618(95) $00001-\mathrm{V}$

19. Atiş, C.D. (2003) Accelerated carbonation and testing of concrete made with fly ash. Constr. Build. Mater. 17[3], 147-152. https://doi.org/10.1016/S0950-0618(02)00116-2

20. Rozière, E.; Loukili, A.; Cussigh, F. (2009) A performance based approach for durability of concrete exposed to carbonation. Constr. Build. Mater. 23[1], 190-199. https://doi. org/10.1016/j.conbuildmat.2008.01.006

21. Hussain, S.; Bhunia, D.; Singh, S.B. (2017) Comparative study of accelerated carbonation of plain cement and fly-ash concrete. J. Build. Eng. 10, 26-31. https://doi.org/10.1016/j. jobe.2017.02.001

22. Villain, G. Thiery, M · V, B-B.; Platret, G. (2007) Different methods to measure the carbonation profiles in concrete. In: Baroghel-Bouny V, Andrade C, Torrent R, Scrivener $\mathrm{K}$ (eds) International RILEM Workshop on Performance Based Evaluation and Indicators for Concrete Durability. RILEM Publications, Madrid, 89-98.

23. Younsi, A.; Turcry, P.; Aït-Mokhtar, A.; Staquet, S. (2013) Accelerated carbonation of concrete with high content of mineral additions: Effect of interactions between hydration and drying. Cem. Concr. Res. 43[1], 25-33. https://doi. org/10.1016/j.cemconres.2012.10.008

24. Turcry, P.; Oksri-Nelfia, L.; Younsi, A.; Aït-Mokhtar, A. (2014) Analysis of an accelerated carbonation test with severe preconditioning. Cem. Concr. Res. 57, 70-78. https:// doi.org/10.1016/j.cemconres.2014.01.003

25. Borges, P.H.R.; Costa, J.O.; Milestone, N.B.; Lynsdale, C.J.; Streatfield, R.E. (2010) Carbonation of CH and C-S-H in composite cement pastes containing high amounts of BFS. Cem. Concr. Res. 40[2], 284-292. https://doi.org/10.1016/j. cemconres.2009.10.020

26. Brouwers, H. (2003) Chemical reactions in hydrated ordinary Portland cement based on the work by powers and brownyard. In: Fisher HB (ed) 15th Ibausil (Internationale Baustofftagung). F.A. Finger Institut für Baustoffkunde, Weimar, Germany, pp. 1-0553-1-0566.

27. Gartner, E.; Maruyama, I.; Chen, J. (2017) A new model for the C-S-H phase formed during the hydration of 
Portland cements. Cem. Concr. Res. 97, 95-106. https://doi. org/10.1016/j.cemconres.2017.03.001

28. Drouet, E.; Poyet, S.; Le Bescop, P.; Torrenti, J.-M.; Bourbon, X. (2019) Carbonation of hardened cement pastes: Influence of temperature. Cem. Concr. Res. 115, 445-459. https://doi.org/10.1016/j.cemconres.2018.09.019

29. Ashraf, W. (2016) Carbonation of cement-based materials: Challenges and opportunities. Constr. Build. Mater. 120, 558-570. https://doi.org/10.1016/j.conbuildmat.2016. 05.080

30. Wang, A.; Zhang, C.; Sun, W. (2004) Fly ash effects: II. The active effect of fly ash. Cem. Concr. Res. 34[11], 2057-2060. https://doi.org/10.1016/j.cemconres.2003.03.001

31. Parrott, L.J. (1996) Some effects of cement and curing upon carbonation and reinforcement corrosion in concrete. Mater. Struct. 29, 164-173. https://doi.org/10.1007/bf02486162

32. Liu, P.; Chen, Y.; Yu, Z. (2019) Effects of temperature, relative humidity and $\mathrm{CO}_{2}$ concentration on concrete carbonation. Mag. Concr. Res. 1-44. https://doi.org/10.1680/ jmacr.18.00496

33. Li, Z.; Fang, F.; Tang, X.; Cai, N. (2012) Effect of temperature on the carbonation reaction of $\mathrm{CaO}$ with $\mathrm{CO}_{2}$. Energy \& Fuels. 26[4], 2473-2482. https://doi.org/10.1021/ ef201543n

34. Park, D.C. (2008) Carbonation of concrete in relation to $\mathrm{CO} 2$ permeability and degradation of coatings. Constr. Build. Mater. 22[11], 2260-2268. https://doi.org/10.1016/j. conbuildmat.2007.07.032

35. Thiery, M.; Villain, G.; Dangla, P.; Platret, G. (2007) Investigation of the carbonation front shape on cementitious materials: Effects of the chemical kinetics. Cem. Concr. Res. 37[7], 1047-1058. https://doi.org/10.1016/j. cemconres.2007.04.002

36. Silva, A.; Neves, R.; De Brito, J. (2014) Statistical modelling of carbonation in reinforced concrete. Cem. Concr. Compos. 50, 73-81. https://doi.org/10.1016/j.cemconcomp. 2013.12.001

37. Sola, J.; Sevilla, J. (1997) Importance of input data normalization for the application of neural networks to complex industrial problems. IEEE Trans. Nucl. Sci. 44[3], 1464-1468. https://doi.org/10.1109/23.589532
38. Uwanuakwa, I.D. (2019) ANN Regression MATLAB code. https://doi.org/10.13140/RG.2.2.29835.95528

39. Taffese, W.Z.; Al-Neshawy, F.; Sistonen, E.; Ferreira, M. (2015) Optimized neural network based carbonation prediction model. In: International Symposium Non-Destructive Testing in Civil Engineering (NDT-CE). Berlin, Germany, pp. $1074-1083$

40. Kellouche, Y.; Boukhatem, B.; Ghrici, M.; Tagnit-Hamou, A. (2019) Exploring the major factors affecting fly-ash concrete carbonation using artificial neural network. Neural. Comput. Appl. 31[S2], 969-988. https://doi.org/10.1007/ s00521-017-3052-2

41. Arandigoyen, M.; Álvarez, J.I.; Álvarez, J.I. (2006) Pore structure and carbonation in blended lime-cement pastes. Mater. Construcc. 56[282], 17-30. https://doi.org/10.3989/ mc.2006.v56.i282.24

42. Elmoaty, A.E.M.A. (2018) Four-years carbonation and chloride induced steel corrosion of sulfate-contaminated aggregates concrete. Constr. Build. Mater. 163, 539-556. https://doi.org/10.1016/j.conbuildmat.2017.12.128

43. Katz, A.; Bentur, A.; Wasserman, R. (2015) Effect of cement content on concrete durability. In: Quattrone M, John VM (eds) XIII International Conference on Durability of Building Materials and Components - XIII DBMC. RILEM Publications, Sao Paulo, Brazil, 1137-1142.

44. Khunthongkeaw, J.; Tangtermsirikul, S. Leelawat, T. (2006) A study on carbonation depth prediction for fly ash concrete. Constr. Build. Mater. 20[9], 744-753. https://doi. org/10.1016/j.conbuildmat.2005.01.052

45. Quan, H.; Kasami, H. (2013) Experimental study on effects of type and replacement ratio of fly ash on strength and durability of concrete. Open. Civ. Eng. J. 7[1], 93-100. https://doi.org/10.2174/1874149520130708004

46. Samenow, J. (2016) Two Middle East locations hit 129 degrees, hottest ever in Eastern Hemisphere, maybe the world. Washington Post.

47. Chen, S.; Sun, W.; Zhang, Y.; Guo, F. (2008) Carbonation depth prediction of fly ash concrete subjected to 2-and 3-dimensional $\mathrm{CO}_{2}$ attack. Front. Archit. Civ. Eng. China. 2[4], 395-400. https://doi.org/10.1007/s11709008-0046-2 